\title{
Reducing Surface Recombination by a Poly(4-vinylpyridine) Interlayer in Perovskite Solar Cells with High Open-Circuit Voltage and Efficiency
}

Mozhgan Yavari, ${ }^{\dagger} \ddagger$ Mohammad Mazloum-Ardakani, ${ }^{*}, \ddagger$ Somayeh Gholipour,,$\|_{\odot}$

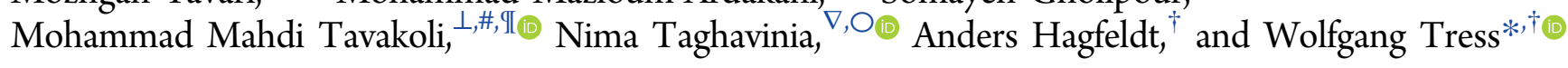

${ }^{\dagger}$ Laboratory of Photomolecular Science, École Polytechnique Fédérale de Lausanne, Station 6, CH-1015 Lausanne, Switzerland

${ }^{\ddagger}$ Department of Chemistry, Yazd University, 89195-741 Yazd, Iran

${ }^{\S}$ Department of Physics, Alzahra University, 1993891176 Tehran, Iran

"Non-metallic Materials Research Department, Niroo Research Institute (NRI), 14665517 Tehran, Iran

${ }^{\perp}$ Department of Electrical Engineering and Computer Science, Massachusetts Institute of Technology, MA02139 Cambridge, United States

\# Department of Materials Science and Engineering, Sharif University of Technology, 113659466 Tehran, Iran

${ }^{I}$ Laboratory for Photonics and Interfaces, École Polytechnique Fédérale de Lausanne, 1015 Lausanne, Switzerland

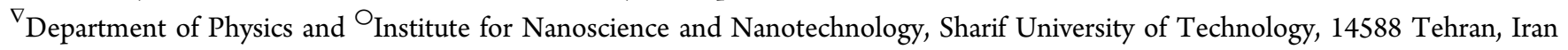

Supporting Information

ABSTRACT: Identifying and reducing the dominant recombination processes in perovskite solar cells is one of the major challenges for further device optimization. Here, we show that introducing a thin interlayer of poly(4-vinylpyridine) (PVP) between the perovskite film and the hole transport layer reduces nonradiative recombination. Employing such a PVP interlayer, we reach an open-circuit voltage of $1.20 \mathrm{~V}$ for the best devices and a stabilized efficiency of $20.7 \%$. The beneficial effect of the PVP interlayer is proven by statistical analysis of various samples, many of those showing an open-circuit voltage larger than $1.17 \mathrm{~V}$, and a $30 \mathrm{mV}$ increase in average compared to unmodified samples. The reduced nonradiative recombination is proven by enhanced photo- and electroluminescence yields.
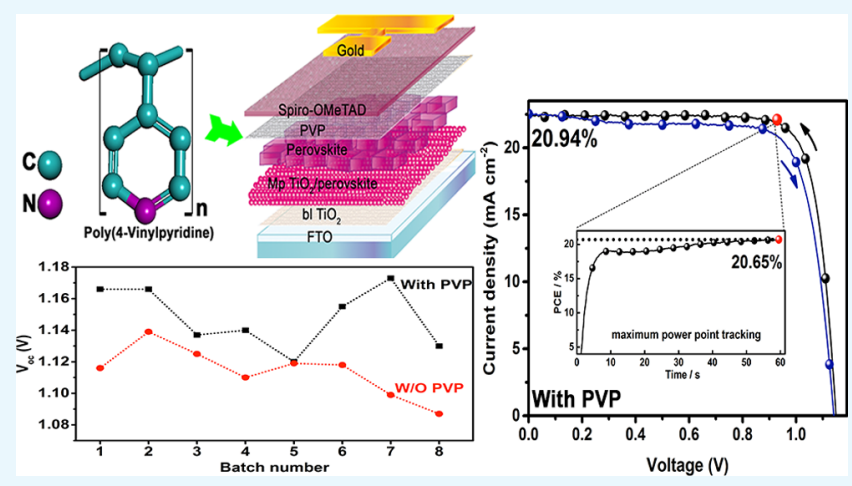

\section{INTRODUCTION}

The past several years have seen the emergence of organicinorganic metal-halide perovskite solar cells. ${ }^{1-3}$ These perovskites are described by the chemical formula $\mathrm{ABX}_{3}$, where $\mathrm{A}=$ cesium (Cs), methylammonium (MA), or formamidinium (FA); $\mathrm{B}=\mathrm{Pb}$ or $\mathrm{Sn}$; and $\mathrm{X}=\mathrm{Cl}, \mathrm{Br}$, or I. Starting from $\mathrm{MAPbI}_{3}{ }^{1}$ A and $\mathrm{X}$ sites have been partially substituted to improve solar cell performance, ${ }^{4-7}$ where extensive optimization leads to an outstanding solar-to-electric power conversion efficiency (PCE) higher than $22 \% .^{8}$ An open-circuit voltage $\left(V_{\text {oc }}\right)$ larger than $1.2 \mathrm{~V}^{9,10}$ has been reached, which is a remarkable value for a material with a band gap of approximately $1.6 \mathrm{eV}$. This exceptional performance has been attributed to the high defect tolerance ${ }^{11}$ and low densities of deep traps ${ }^{12}$ in the material along with high light absorption over the visible spectrum including a sharp absorption onset and charge carrier diffusion lengths in the micrometer range. ${ }^{13-16}$
While photocurrents in efficient $\mathrm{MA}_{x} \mathrm{FA}_{1-x} \mathrm{~Pb}\left(\mathrm{I}_{y} \mathrm{Br}_{1-y}\right)_{3}$ solar cells are already close to their practical limits, there is still room for improvement of $V_{\text {oc }}$ and fill factor. With a theoretical maximum $V_{\text {oc }}$ between 1.32 and $1.36 \mathrm{~V}$ (dependent on the band gap and for the so far best devices), ${ }^{17}$ the experimentally achieved $V_{o c}$ is still strongly limited by nonradiative recombination. Whereas perovskite devices of the first generation suffered from recombination introduced by nonhomogenous rough films, the second generation devices are suspected to be affected by defects in the perovskite layer itself, ${ }^{16}$ where the role of grain boundaries is controversially discussed. ${ }^{10,18,19}$ Furthermore, interfaces to the contact layers are receiving considerable attention because of the fact that employing nonselective contacts results in low $V_{\text {oc }}{ }^{17,20}$ Zarazua

Received: March 23, 2018

Accepted: April 25, 2018

Published: May 9, 2018 
et al. have shown that recombination at the $\mathrm{TiO}_{2}$ contact dominates the charge carrier lifetime and therefore $V_{\mathrm{oc}}{ }^{21}$ Studying $\mathrm{SnO}_{2}$-based devices, Correa-Baena et al. found that recombination at the hole transport layer $(\mathrm{HTL})$ tetrakis $(\mathrm{N}, \mathrm{N}$ di- p-methoxyphenyl-amine)9,9'-spirobifluorene (spiro-OMeTAD) affects $V_{\text {oc }}$, where a reduction of the dopant concentration can enhance $V_{\text {oc }}$ toward values larger than 1.2 $\mathrm{V}^{10}$

The work presented here is motivated by that study. A thin layer of the wide band gap polymer poly(4-vinylpyridine) (PVP) is introduced as an interlayer between the perovskite and the spiro-OMeTAD, and its effect as a selective layer is investigated. Similar concepts of interface modification [e.g., by phenyl-C61-butyric acid methyl ester (PCBM) or poly(methyl methacrylate) (PMMA)] have been applied to the interface with the electron transport layer ${ }^{22-24}$ and the poly(3,4ethylenedioxythiophene) polystyrene sulfonate (PEDOT:PSS) HTL in inverted devices. ${ }^{25-27}$ Improvements of performance have been ascribed to low leakage currents and reduced recombination at the interfaces. Additionally, compositional changes of mixed perovskite films are reported to reduce surface recombination and enhance $V_{\text {oc }}$ and PCE. ${ }^{28}$ Passivation of surface states employing the Lewis bases thiophene and pyridine has been reported to decrease nonradiative recombination and to facilitate a $V_{\text {oc }}$ of $1.05 \mathrm{~V}$ already in the early days of $\mathrm{MAPbI}_{3}$ solar cell research. ${ }^{29}$

Recently, PVP was employed on top of a noncompact perovskite layer to enhance $V_{\text {oc }}$ toward $1.05 \mathrm{~V} .^{30}$ Very recently, PVP was added to the methylammonium iodide solution during a two-step deposition method, where it is supposed to act as a passivation agent in the perovskite film, which resulted in a $V_{\text {oc }}$ up to $1.15 \mathrm{~V}$ in a planar architecture. ${ }^{31}$ Our work employs PVP for the first time as a selective layer on top of a smooth perovskite film and already high- $V_{\text {oc }}$ reference devices, yielding reproducibly higher $V_{\text {oc }}$ than nonmodified devices with a maximum of $1.20 \mathrm{~V}$ and a stabilized PCE of $20.7 \%$.

\section{RESULTS AND DISCUSSION}

Figure 1a depicts the structure of PVP, and Figure $1 \mathrm{~b}$ shows a schematic of a device composed of a fluorine-doped tin oxide

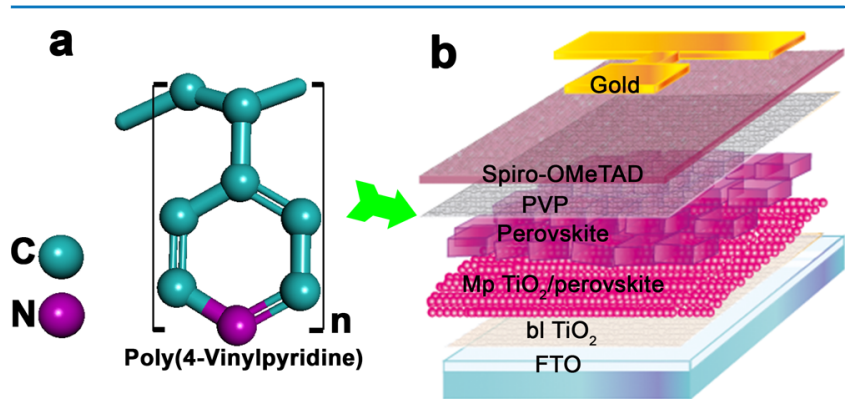

Figure 1. Materials and device. (a) 3D structure of PVP and (b) schematic of the perovskite solar cell. The PVP is placed between the perovskite and the HTL.

(FTO) electrode, a 20-30 nm thin compact $\mathrm{TiO}_{2}$ layer, a $\approx 150 \mathrm{~nm}$ thick mesoporous $\mathrm{TiO}_{2}$ layer, and $\mathrm{a} \approx 500 \mathrm{~nm}$ perovskite layer of the nominal composition " $\mathrm{Cs}_{0.05}\left(\mathrm{MA}_{0.17} \mathrm{FA}_{0.83}\right)_{0.95} \mathrm{~Pb}\left(\mathrm{I}_{0.83} \mathrm{Br}_{0.17}\right)_{3}$ ". ${ }^{32}$ It is covered with a $200 \mathrm{~nm}$ HTL spiro-OMeTAD and an $80 \mathrm{~nm}$ gold electrode. The PVP is introduced as a thin interlayer on top of the perovskite by spin-coating from a solution of $0.1 \mathrm{mg} \mathrm{mL}^{-1}$ in isopropanol $(6000 \mathrm{rpm})$, prior to depositing the HTL. The deposition conditions were obtained by an optimization study yielding a suitable thickness. It was found that the subsequent deposition of the HTL in chlorobenzene does not dissolve the PVP layer.

Comparing devices with and without PVP reveals that the $V_{\text {oc }}$ is systematically higher when PVP is added. The statistics of devices prepared in eight batches shows that both average and extreme values are higher for PVP-modified devices (Figure $2 a$ ). However, because of variations in the quality of the perovskite and the $\mathrm{TiO}_{2}$ layer, the spread of $V_{\text {oc }}$ is large. Therefore, we added a comparison of the maximum $V_{\mathrm{oc}}$ in each batch (Figure 2b), which clearly shows that PVP-modified devices show higher $V_{\text {oc }}$. The spread of $V_{\text {oc }}$ and the sometimes more, sometimes less pronounced effect of PVP indicate that slight changes in each component during fabrication such as the electron-selective layer or the perovskite film affect recombination and can limit performance in high- $V_{\text {oc }}$ devices. This is consistent with the different findings on dominant recombination processes in the literature as mentioned in the introduction of this article.

Figure 2c,d shows current-voltage $(J V)$ curves of one of the best performing devices with and without PVP that have been fabricated for this study. Table 1 displays the respective characteristic parameters. The beneficial effect of an increased $V_{\text {oc }}$ from 1.11 to $1.15 \mathrm{~V}$ is also visible in the PCE, which is increased from 18.6 to $20.7 \%$, measured as a stabilized maximum power output during maximum power point (MPP) tracking. The measured short-circuit current density is close to the value expected from the incident-photon-tocurrent-efficiency (IPCE) shown in Figure S1.

To exclude that the improvement in $V_{\text {oc }}$ is caused just by the solvent (isopropanol) treatment, we coated the perovskite with pure isopropanol. In that case, $V_{\text {oc }}$ remains unmodified as shown by the data in Figure S2. Thus, we conclude that the PVP layer itself is beneficial for $V_{\mathrm{oc}}$ by reducing nonradiative recombination.

To investigate whether the effect of PVP is an enhancement of contact selectivity or a chemical passivation of the perovskite surface, we measure photoluminescence $(\mathrm{PL})$ on unmodified and modified perovskite films on glass. We also use PMMAcovered films as a further reference. Figure 3a shows the respective PL spectra. Keeping the geometry and parameters of the measurement setup unmodified, we are able to compare absolute spectra. We observe that the PL intensity of the perovskite film covered with PMMA is slightly higher than that of the control (W/O PVP) perovskite film. However, employing PVP on top of the perovskite film, the PL intensity is strongly increased. Interestingly, this effect is only observed when the sample is additionally covered by PMMA which might act as a moisture barrier. The considerably higher PL emission observed only for PVP treatment indicates that the enhancement of $V_{\mathrm{oc}}$ is mainly due to a passivation of surface defects on the perovskite in accordance to the hypothesis raised for pyridine treatment. ${ }^{29}$ The slightly higher PL for a thicker PVP layer can be explained by a better surface coverage. However, this finding does not reveal the microscopic origin of the passivation effect, which could be not only due to a reduction of surface defects but also due to, for example, a reduction of the Huang-Rhys factor, describing the electronphonon coupling. ${ }^{33,34}$ Furthermore, it is not completely excluded that the PVP interlayer in the solar cell might also be beneficial in reducing interface recombination at the spiro- 


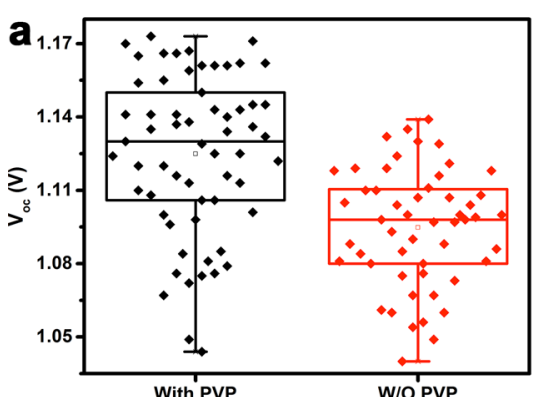

C

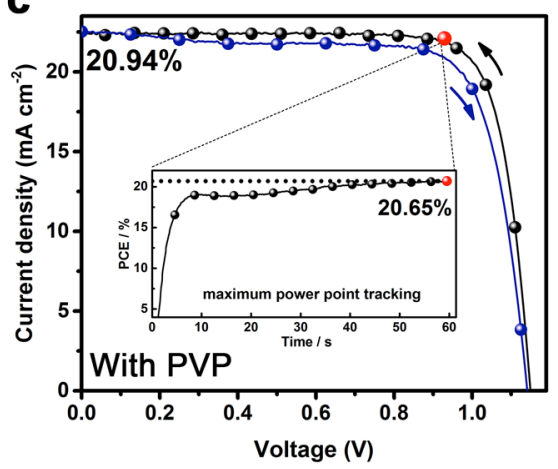

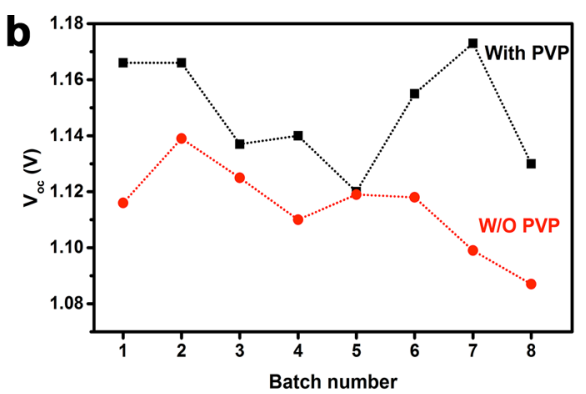

d

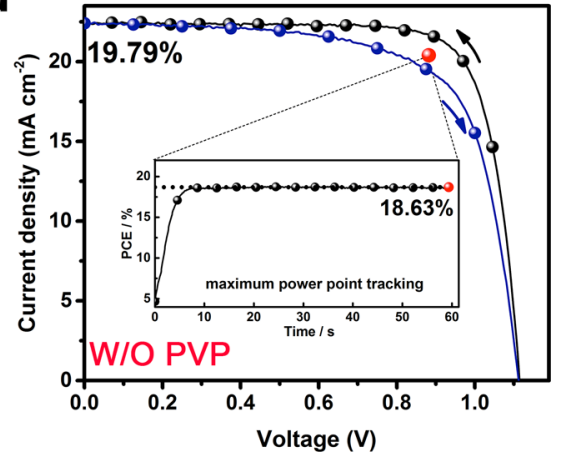

Figure 2. Photovoltaic characteristics. (a) $V_{\mathrm{oc}}$ for devices with and without PVP modification. (b) Comparison of maximum $V_{\mathrm{oc}}$ of devices with and without PVP from each batch. (c,d) Current-voltage characteristics for one of the best performing devices under each condition in this study measured in reverse and forward sweep $\left(10 \mathrm{mV} \mathrm{s}^{-1}\right)$. All measurements were obtained under simulated sun light and using an aperture of $0.16 \mathrm{~cm}^{2}$ $\left(0.25 \mathrm{~cm}^{2}\right.$ electrode area).

Table 1. Characteristic Parameters of the Devices Presented in Figure $2 \mathrm{c}, \mathrm{d}^{a}$

\begin{tabular}{|c|c|c|c|c|c|c|}
\hline cell type & $\begin{array}{c}\text { scan } \\
\text { direction }\end{array}$ & $\begin{array}{l}V_{\mathrm{oc}} \\
(\mathrm{V})\end{array}$ & $\left(\mathrm{mA} \mathrm{cm}^{J_{\mathrm{sc}}}\right)$ & $\mathrm{FF}$ & $\begin{array}{l}\text { PCE } \\
(\%)\end{array}$ & $\begin{array}{l}\text { MPP } \\
\text { PCE } \\
(\%)\end{array}$ \\
\hline \multirow{2}{*}{ W/O PVP } & backward & 1.11 & 22.6 & 0.79 & 19.8 & \multirow{2}{*}{18.6} \\
\hline & forward & 1.11 & 22.6 & 0.69 & 17.5 & \\
\hline \multirow{2}{*}{ with PVP } & backward & 1.15 & 22.1 & 0.81 & 20.9 & \multirow{2}{*}{20.7} \\
\hline & forward & 1.14 & 22.7 & 0.79 & 19.6 & \\
\hline
\end{tabular}

OMeTAD (electrons in the perovskite with holes in the spiro$\mathrm{OMeTAD}$ ) by acting as a tunneling layer and reducing the wave function overlap.

To investigate whether enhanced luminescence efficiency can be observed in the solar cell devices as well, we performed electroluminescence (EL) measurements on representative high- $V_{\text {oc }}$ devices. As shown in Figure $3 \mathrm{~b}$, we detect an increased external EL efficiency by approximately 1 order of magnitude, approaching 0.05 and $0.7 \%$, respectively, at an injection current equaling the short-circuit current under sunlight. These values imply a reduction of the nonradiative $V_{\text {oc }}$ loss by $\approx 60 \mathrm{mV}$, which is consistent with the $V_{\text {oc }}$ measured on these devices without an aperture (1.13 and $1.19 \mathrm{~V})$ and the overall trend.

Furthermore, we investigate $V_{o c}$ as a function of the illumination intensity following the procedure described in ref 35. We observe that the differences in $V_{\text {oc }}$ are maintained independent of illumination intensity (Figure 3c). The slope remains unmodified, and deduced ideality factors of 1.5-1.6 (at high light intensities) are comparable (Figure 3d); the increased values for lower intensity are predominantly due to shunts. This finding indicates that the PVP treatment does not dramatically change the recombination mechanism but the nonradiative recombination rate independent of charge carrier density and voltage. The often proposed idea of trap filling with higher charge carrier densities cannot be observed here; neither an effect of enhanced surface recombination for higher light intensities. The latter would result in a reduction of the ideality factor with light intensity as observed in organic solar cells with low built-in potential. ${ }^{36}$ In the case here, the PVP passivates defects on the perovskite surface, possibly including surfaces (of grains) that penetrate into the interior of the film.

\section{CONCLUSIONS}

In conclusion, we have shown that PVP deposited between the perovskite and the HTL reduces nonradiative recombination. The $V_{\text {oc }}$ has been increased up to $1.20 \mathrm{~V}$, and a stabilized efficiency of $20.7 \%$ has been reached. Using PL and EL measurements and analyzing the diode ideality factor, we have found that PVP mainly passivates defect states on the perovskite surface and possibly at the interface with the HTL, which otherwise act as recombination centers. Our study indicates that both interfaces and bulk of the perovskite have to be further optimized to reduce nonradiative recombination to reach reproducibly a $V_{\text {oc }}$ larger than $1.2 \mathrm{~V}$.

\section{EXPERIMENTAL SECTION}

Fabrication of Films for Spectroscopy. The samples were fabricated on cleaned, plasma-etched glass substrates, where the perovskite precursor solution was spin-coated onto the glass directly after UV-ozone treatment. Subsequent to the deposition of the perovskite layer, the substrates were annealed for $1 \mathrm{~h}$ at $100{ }^{\circ} \mathrm{C}$. The films were then spin-coated with PVP (Aldrich) solution $\left(0.1 \mathrm{mg} \mathrm{mL}^{-1}\right.$ in isopropanol) for $30 \mathrm{~s}$ at $6000 \mathrm{rpm}$ with a ramp of $2000 \mathrm{rpm} \mathrm{s}^{-1}$, followed by annealing at $70{ }^{\circ} \mathrm{C}$ for $20 \mathrm{~min}$, and/or $10 \mathrm{mg} \mathrm{mL}^{-1}$ solution of PMMA (Aldrich) spin-coated for $20 \mathrm{~s}$ at $1000 \mathrm{rpm}$ with a ramp of 500 

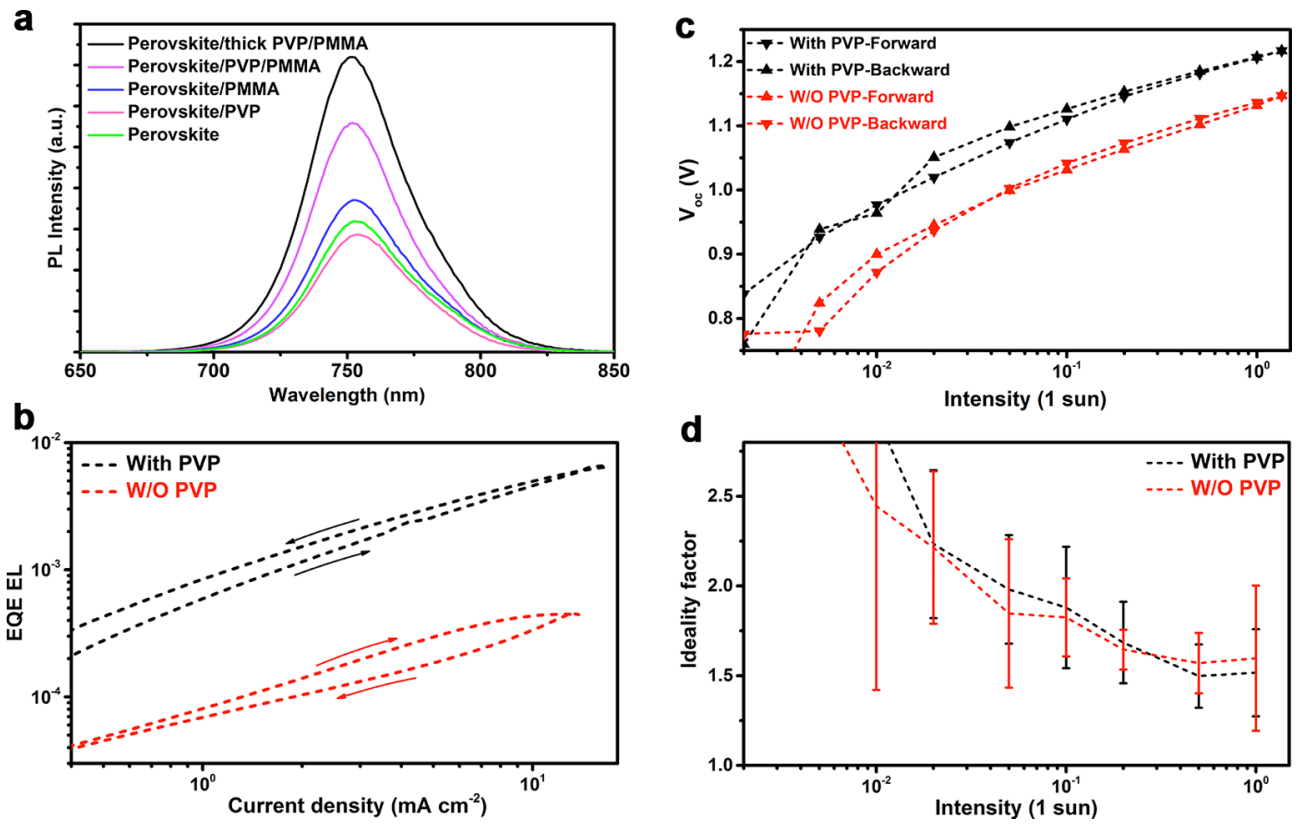

Figure 3. Characterization of recombination. (a) PL spectra of perovskite layers on glass with different top layer(s), (b) external EL yield as a function of injection current detected during a voltage loop with a sweep rate of $20 \mathrm{mV} \mathrm{s}{ }^{-1}$, (c) $V_{\text {oc }}$ as a function of illumination intensity obtained from an intensity sweep from low to high intensity and back (settling time $5 \mathrm{~s}$ ), and (d) differential ideality factor obtained from an analysis of $V_{\text {oc }} \mathrm{vs}$ light intensity for several devices. The error bars show that determining the differential ideality factor in these devices leads to errors in the range of \pm 0.2 .

$\mathrm{rpm} \mathrm{s}^{-1}$. For thicker PVP films, the parameters were changed to $30 \mathrm{~s}$ and $1000 \mathrm{rpm}$ with a ramp of $500 \mathrm{rpm} \mathrm{s}^{-1}$.

Solar Cell Fabrication and Electron-Selective Layer Preparation. FTO substrates $\left(10 \Omega \mathrm{sq}^{-1}\right.$, Nippon Sheet Glass) were etched with zinc powder and $\mathrm{HCl}(4 \mathrm{M})$ to form the electrode pattern. Glass sheets were ultrasonically cleaned by a sequential (15 min), 2\% Hellmanex water solution, deionized water, ethanol, and acetone. Substrates were further cleaned with UV-ozone treatment for $15 \mathrm{~min}$. A 20-30 nm $\mathrm{TiO}_{2}$ compact layer was then deposited on the clean preheated FTO substrates by spray pyrolysis from a precursor solution of titanium diisopropoxide bis(acetylacetonate) in anhydrous ethanol, using oxygen as the carrier gas on a hot plate set to $450{ }^{\circ} \mathrm{C}$, followed by annealing at $450{ }^{\circ} \mathrm{C}$, for $30 \mathrm{~min}$ in air. A mesoporous $\mathrm{TiO}_{2}$ layer was deposited on compact $\mathrm{TiO}_{2} / \mathrm{FTO}$ substrates via spin-coating of $30 \mathrm{~nm}$ particle size paste (Dyesol $30 \mathrm{NR}-\mathrm{D})$ diluted in ethanol $\left(150 \mathrm{mg} \mathrm{mL}^{-1}\right)$ at $4000 \mathrm{rpm}$ for $20 \mathrm{~s}$ with a ramp of $2000 \mathrm{rpm} \mathrm{s}^{-1}$ to achieve a $\sim 150 \mathrm{~nm}$ layer thickness. The substrates were immediately dried at $100{ }^{\circ} \mathrm{C}$ for $10 \mathrm{~min}$ and then sintered again at $450{ }^{\circ} \mathrm{C}$ for 30 min under dry air flow.

Li doping of mesoporous $\mathrm{TiO}_{2}$ was accomplished by spincoating a $0.1 \mathrm{M}$ solution of bis(trifluoromethylsulphonyl)imide lithium salt (Li-TFSI) in acetonitrile at $3000 \mathrm{rpm}$ with a ramp of $1000 \mathrm{rpm} \mathrm{s}^{-1}$ for $10 \mathrm{~s}$ and $\mathrm{Li}^{+}$-treated substrates followed by another sintering step at $450{ }^{\circ} \mathrm{C}$ for $30 \mathrm{~min} .{ }^{37}$ After cooling down to $150{ }^{\circ} \mathrm{C}$, the substrates were immediately transferred to an argon atmosphere glovebox for depositing the perovskite films.

Perovskite Precursor Solution and Film Preparation. The organic monovalent cation salts were purchased from Dyesol; the lead compound was purchased from TCI; and CsI was purchased from abcr $\mathrm{GmbH}$. The "Cs containing-mixed perovskite" precursor solution was prepared by dissolving FAI (1 M), CsI (0.05 M), $\mathrm{PbI}_{2}(1.1 \mathrm{M}), \mathrm{MABr}(0.2 \mathrm{M})$, and $\mathrm{PbBr}_{2}$
(0.22 M) in anhydrous dimethylformamide/dimethyl sulfoxide $4: 1(\mathrm{v} / \mathrm{v})$, as reported earlier by us. ${ }^{32}$ The respective perovskite solution was spin-coated in a two-step procedure at 1000 and $6000 \mathrm{rpm}$ for 10 and $20 \mathrm{~s}$, respectively. During the second step, $200 \mu \mathrm{L}$ of chlorobenzene was poured on the spinning substrate $5 \mathrm{~s}$ before the end of the procedure. The substrates were then annealed at $100{ }^{\circ} \mathrm{C}$ for $1 \mathrm{~h}$ on a hot plate in the argon-filled glovebox.

Passivation Layer, Hole Transporting Layer, and Top Electrode. After the perovskite annealing, the substrates were cooled down for a few minutes, and PVP (Sigma-Aldrich) solution $\left(0.1 \mathrm{mg} \mathrm{mL}^{-1}\right.$ in isopropanol) was spin-coated at 6000 $\mathrm{rpm}$ with a ramp of $2000 \mathrm{rpm} \mathrm{s}^{-1}$ for $30 \mathrm{~s}$, and the substrates were then annealed at $70{ }^{\circ} \mathrm{C}$ for $20 \mathrm{~min}$. After the PVP annealing, the substrates were cooled down for a few minutes, and a spiro-OMeTAD (Merck) solution (70 $\mathrm{mM}$ in chlorobenzene) was spin-casted at $4000 \mathrm{rpm}$ for $20 \mathrm{~s}$. SpiroOMeTAD was doped with Li-TFSI (Sigma-Aldrich), tris(2(1H-pyrazol-1-yl)-4-tert-butylpyridine)-cobalt(III) tris(bis(trifluoromethylsulphonyl)imide) (FK209, Dyenamo), and 4tert-butylpyridine (TBP, Sigma-Aldrich). The molar ratio of additives for spiro-OMeTAD was $0.5,0.03$, and 3.3 for Li-TFSI, FK209, and TBP, respectively. Finally, the $80 \mathrm{~nm}$ gold top electrode was thermally evaporated under high vacuum. The active area was $0.25 \mathrm{~cm}^{2}$.

Perovskite Solar Cell Characterization. Solar cells were measured using a $450 \mathrm{~W}$ xenon light source (Oriel). The spectral mismatch between AM1.5G and the simulated illumination was reduced by using a Schott K113 Tempax filter (Präzisions Glas \& Optik $\mathrm{GmbH}$ ). The light intensity was calibrated with a Si photodiode equipped with an infrared cutoff filter (KG3, Schott), and it was recorded during each measurement. Current-voltage characteristics of the cells were obtained by applying an external voltage bias while measuring the current response with a digital source meter 
(Keithley 2400). The voltage scan rate was $10 \mathrm{mV} \mathrm{s}^{-1}$, and no device preconditioning, such as prolonged light soaking or forward voltage bias, was applied before starting the measurement. The starting voltage was determined as the potential at which the cells furnish $1 \mathrm{~mA}$ in forward bias; no equilibration time was used. The cells were masked with a black metal mask, limiting the active area to $0.16 \mathrm{~cm}^{2}$ and reducing the influence of the scattered light.

Steady-state PL was measured using a Fluorolog, HORIBA Jobin Yvon, FL-1065. A white tungsten lamp was used as the light source. A monochromator was placed between the sample and the light source as well as between the sample and the detector. An excitation wavelength of $450 \mathrm{~nm}$ was used for all the samples. The emission spectrum was measured from $10 \mathrm{~nm}$ higher than the emission spectrum to $850 \mathrm{~nm}$ in steps of one $\mathrm{nm}$. An integration time of $1 \mathrm{~s}$ was used for each wavelength. The excitation source and the detector were placed at $90^{\circ}$ with respect to each other. The sample was oriented $60^{\circ}$ with respect to the excitation source to decrease interference from reflected light.

Open-circuit voltage as a function of illumination intensity was measured using white LEDs. The devices were left unmasked at room temperature and under constant nitrogen flow to prevent degradation during operation. The data were analyzed as described in ref 35.

EL yield was measured by applying a potential sweep to the device and by recording the emitted photon flux with a calibrated, large area $\left(1 \mathrm{~cm}^{2}\right) \mathrm{Si}$ photodiode (Hamamatsu S1227-1010BQ) placed directly on top of the sample. The driving voltage was applied using a Bio-Logic SP300 potentiostat, which was also used to measure the short-circuit current of the detector at a second channel.

The IPCE spectra were measured with a system operating in the dc mode and a $300 \mathrm{~W}$ Xe lamp as the light source combined with a monochromator (Arkeo-Ariadne, Cicci Research s.r.l.). No bias light was applied.

\section{ASSOCIATED CONTENT}

\section{S Supporting Information}

The Supporting Information is available free of charge on the ACS Publications website at DOI: 10.1021/acsomega.8b00555.

Details concerning characterization, additional $J-V$ statistics, and IPCE (PDF)

\section{AUTHOR INFORMATION}

\section{Corresponding Authors}

*E-mail: Mazloum@yazd.ac.ir (M.M.-A.).

*E-mail: wolfgang.tress@epfl.ch (W.T.).

\section{ORCID}

Mozhgan Yavari: 0000-0002-9321-3405

Somayeh Gholipour: 0000-0001-8935-4515

Mohammad Mahdi Tavakoli: 0000-0002-8393-6028

Nima Taghavinia: 0000-0001-6815-2041

Wolfgang Tress: 0000-0002-4010-239X

Notes

The authors declare no competing financial interest.

\section{ACKNOWLEDGMENTS}

M.Y. and S.G. acknowledge the Ministry of Science, Research and Technology of Iran for financial support. W.T. thanks the
Swiss National Science foundation for funding through an Ambizione fellowship.

\section{REFERENCES}

(1) Kojima, A.; Teshima, K.; Shirai, Y.; Miyasaka, T. Organometal Halide Perovskites as Visible-Light Sensitizers for Photovoltaic Cells. J. Am. Chem. Soc. 2009, 131, 6050-6051.

(2) Burschka, J.; Pellet, N.; Moon, S.-J.; Humphry-Baker, R.; Gao, P.; Nazeeruddin, M. K.; Grätzel, M. Sequential Deposition as a Route to High-Performance Perovskite-Sensitized Solar Cells. Nature 2013, 499, 316-319.

(3) Correa-Baena, J.-P.; Abate, A.; Saliba, M.; Tress, W.; Jacobsson, T. J.; Grätzel, M.; Hagfeldt, A. The Rapid Evolution of Highly Efficient Perovskite Solar Cells. Energy Environ. Sci. 2017, 10, 710-727.

(4) Beal, R. E.; Slotcavage, D. J.; Leijtens, T.; Bowring, A. R.; Belisle, R. A.; Nguyen, W. H.; Burkhard, G. F.; Hoke, E. T.; McGehee, M. D. Cesium Lead Halide Perovskites with Improved Stability for Tandem Solar Cells. J. Phys. Chem. Lett. 2016, 7, 746-751.

(5) Pellet, N.; Gao, P.; Gregori, G.; Yang, T.-Y.; Nazeeruddin, M. K.; Maier, J.; Grätzel, M. Mixed-Organic-Cation Perovskite Photovoltaics for Enhanced Solar-Light Harvesting. Angew. Chem., Int. Ed. 2014, 53, 3151-3157.

(6) Jeon, N. J.; Noh, J. H.; Yang, W. S.; Kim, Y. C.; Ryu, S.; Seo, J.; Seok, S. I. Compositional Engineering of Perovskite Materials for High-Performance Solar Cells. Nature 2015, 517, 476-480.

(7) Bi, D.; Tress, W.; Dar, M. I.; Gao, P.; Luo, J.; Renevier, C.; Schenk, K.; Abate, A.; Giordano, F.; Baena, J.-P. C.; et al. Efficient Luminescent Solar Cells Based on Tailored Mixed-Cation Perovskites. Sci. Adv. 2016, 2, No. e1501170.

(8) Yang, W. S.; Park, B.-W.; Jung, E. H.; Jeon, N. J.; Kim, Y. C.; Lee, D. U.; Shin, S. S.; Seo, J.; Kim, E. K.; Noh, J. H.; et al. Iodide Management in Formamidinium-Lead-Halide-based Perovskite Layers for Efficient Solar Cells. Science 2017, 356, 1376-1379.

(9) Saliba, M.; Matsui, T.; Domanski, K.; Seo, J.-Y.; Ummadisingu, A.; Zakeeruddin, S. M.; Correa-Baena, J.-P.; Tress, W. R.; Abate, A.; Hagfeldt, A.; et al. Incorporation of Rubidium Cations into Perovskite Solar Cells Improves Photovoltaic Performance. Science 2016, 354, 206.

(10) Correa-Baena, J.-P.; Tress, W.; Domanski, K.; Halvani Anaraki, E.; Turren-Cruz, S.-H.; Roose, B.; Boix, P. P.; Grätzel, M.; Saliba, M.; Abate, A.; et al. Identifying and Suppressing Interfacial Recombination to Achieve High Open-Circuit Voltage in Perovskite Solar Cells. Energy Environ. Sci. 2017, 10, 1207-1212.

(11) Brandt, R. E.; Stevanović, V.; Ginley, D. S.; Buonassisi, T. Identifying Defect-Tolerant Semiconductors with High MinorityCarrier Lifetimes: Beyond Hybrid Lead Halide Perovskites. MRS Commun. 2015, 5, 265-275.

(12) Shi, D.; Adinolfi, V.; Comin, R.; Yuan, M.; Alarousu, E.; Buin, A.; Chen, Y.; Hoogland, S.; Rothenberger, A.; Katsiev, K.; et al. Low Trap-State Density and Long Carrier Diffusion in Organolead Trihalide Perovskite Single Crystals. Science 2015, 347, 519-522.

(13) Xing, G.; Mathews, N.; Sun, S.; Lim, S. S.; Lam, Y. M.; Grätzel, M.; Mhaisalkar, S.; Sum, T. C. Long-Range Balanced Electron- and Hole-Transport Lengths in Organic-Inorganic CH3NH3PbI3. Science 2013, 342, 344-347.

(14) Stranks, S. D.; Eperon, G. E.; Grancini, G.; Menelaou, C.; Alcocer, M. J. P.; Leijtens, T.; Herz, L. M.; Petrozza, A.; Snaith, H. J. Electron-Hole Diffusion Lengths Exceeding 1 Micrometer in an Organometal Trihalide Perovskite Absorber. Science 2013, 342, 341344 .

(15) De Wolf, S.; Holovsky, J.; Moon, S.-J.; Löper, P.; Niesen, B.; Ledinsky, M.; Haug, F.-J.; Yum, J.-H.; Ballif, C. Organometallic Halide Perovskites: Sharp Optical Absorption Edge and Its Relation to Photovoltaic Performance. J. Phys. Chem. Lett. 2014, 5, 1035-1039.

(16) Tress, W. Perovskite Solar Cells on the Way to Their Radiative Efficiency Limit - Insights Into a Success Story of High Open-Circuit Voltage and Low Recombination. Adv. Energy Mater. 2017, 7, 1602358. 
(17) Tress, W.; Marinova, N.; Inganäs, O.; Nazeeruddin, M. K.; Zakeeruddin, S. M.; Graetzel, M. Predicting the Open-Circuit Voltage of $\mathrm{CH} 3 \mathrm{NH} 3 \mathrm{PbI} 3$ Perovskite Solar Cells Using Electroluminescence and Photovoltaic Quantum Efficiency Spectra: The Role of Radiative and Non-Radiative Recombination. Adv. Energy Mater. 2015, 5, 1400812 .

(18) Long, R.; Liu, J.; Prezhdo, O. V. Unravelling the Effects of Grain Boundary and Chemical Doping on Electron-Hole Recombination in $\mathrm{CH} 3 \mathrm{NH} 3 \mathrm{PbI} 3$ Perovskite by Time-Domain Atomistic Simulation. J. Am. Chem. Soc. 2016, 138, 3884-3890.

(19) Yang, M.; Zeng, Y.; Li, Z.; Kim, D. H.; Jiang, C.-S.; van de Lagemaat, J.; Zhu, K. Grain Boundaries Dominate Non-Radiative Recombination in CH3NH3PbI3 Perovskite Thin Films? Phys. Chem. Chem. Phys. 2017, 19, 5043-5050.

(20) Marinova, N.; Tress, W.; Humphry-Baker, R.; Dar, M. I.; Bojinov, V.; Zakeeruddin, S. M.; Nazeeruddin, M. K.; Grätzel, M. Light Harvesting and Charge Recombination in $\mathrm{CH} 3 \mathrm{NH} 3 \mathrm{PbI} 3$ Perovskite Solar Cells Studied by Hole Transport Layer Thickness Variation. ACS Nano 2015, 9, 4200-4209.

(21) Zarazua, I.; Han, G.; Boix, P. P.; Mhaisalkar, S.; FabregatSantiago, F.; Mora-Seró, I.; Bisquert, J.; Garcia-Belmonte, G. Surface Recombination and Collection Efficiency in Perovskite Solar Cells from Impedance Analysis. J. Phys. Chem. Lett. 2016, 7, 5105-5113.

(22) Shao, Y.; Xiao, Z.; Bi, C.; Yuan, Y.; Huang, J. Origin and Elimination of Photocurrent Hysteresis by Fullerene Passivation in $\mathrm{CH}_{3} \mathrm{NH}_{3} \mathrm{PbI}_{3}$ Planar Heterojunction Solar Cells. Nat. Commun. 2014 5,5784 .

(23) Zhu, Z.; Ma, J.; Wang, Z.; Mu, C.; Fan, Z.; Du, L.; Bai, Y.; Fan, L.; Yan, H.; Phillips, D. L.; et al. Efficiency Enhancement of Perovskite Solar Cells through Fast Electron Extraction: The Role of Graphene Quantum Dots. J. Am. Chem. Soc. 2014, 136, 3760-3763.

(24) Peng, J.; Wu, Y.; Ye, W.; Jacobs, D. A.; Shen, H.; Fu, X.; Wan, Y.; Duong, T.; Wu, N.; Barugkin, C.; et al. Interface Passivation Using Ultrathin Polymer-fullerene Films for High-Efficiency Perovskite Solar Cells with Negligible Hysteresis. Energy Environ. Sci. 2017, 10, $1792-1800$.

(25) Labban, A. E.; Chen, H.; Kirkus, M.; Barbe, J.; Del Gobbo, S.; Neophytou, M.; McCulloch, I.; Eid, J. Improved Efficiency in Inverted Perovskite Solar Cells Employing a Novel Diarylamino-Substituted Molecule as PEDOT: PSS Replacement. Adv. Energy Mater. 2016, 6, 1502101 .

(26) Hou, Y.; Chen, W.; Baran, D.; Stubhan, T.; Luechinger, N. A.; Hartmeier, B.; Richter, M.; Min, J.; Chen, S.; Quiroz, C. O. R.; et al. Overcoming the Interface Losses in Planar Heterojunction PerovskiteBased Solar Cells. Adv. Mater. 2016, 28, 5112-5120.

(27) Tvingstedt, K.; Gil-Escrig, L.; Momblona, C.; Rieder, P.; Kiermasch, D.; Sessolo, M.; Baumann, A.; Bolink, H. J.; Dyakonov, V. Removing Leakage and Surface Recombination in Planar Perovskite Solar Cells. ACS Energy Lett. 2017, 2, 424-430.

(28) Cho, K. T.; Paek, S.; Grancini, G.; Roldán-Carmona, C.; Gao, P.; Lee, Y.; Nazeeruddin, M. K. Highly Efficient Perovskite Solar Cells with a Compositionally Engineered Perovskite/hole Transporting Material Interface. Energy Environ. Sci. 2017, 10, 621-627.

(29) Noel, N. K.; Abate, A.; Stranks, S. D.; Parrott, E. S.; Burlakov, V. M.; Goriely, A.; Snaith, H. J. Enhanced Photoluminescence and Solar Cell Performance via Lewis Base Passivation of Organic-Inorganic Lead Halide Perovskites. ACS Nano 2014, 8, 9815-9821.

(30) Chaudhary, B.; Kulkarni, A.; Jena, A. K.; Ikegami, M.; Udagawa, Y.; Kunugita, H.; Ema, K.; Miyasaka, T. Poly(4-Vinylpyridine)-Based Interfacial Passivation to Enhance Voltage and Moisture Stability of Lead Halide Perovskite Solar Cells. ChemSusChem 2017, 10, 24732479.

(31) Zuo, L.; Guo, H.; deQuilettes, D. W.; Jariwala, S.; Marco, N. D.; Dong, S.; DeBlock, R.; Ginger, D. S.; Dunn, B.; Wang, M.; et al. Polymer-Modified Halide Perovskite Films for Efficient and Stable Planar Heterojunction Solar Cells. Sci. Adv. 2017, 3, No. e1700106.

(32) Saliba, M.; Matsui, T.; Seo, J.-Y.; Domanski, K.; Correa-Baena, J.-P.; Nazeeruddin, M. K.; Zakeeruddin, S. M.; Tress, W.; Abate, A.; Hagfeldt, A.; et al. Cesium-Containing Triple Cation Perovskite Solar
Cells: Improved Stability, Reproducibility and High Efficiency. Energy Environ. Sci. 2016, 9, 1989-1997.

(33) Kirchartz, T.; Rau, U. What Makes a Good Solar Cell? Adv. Energy Mater. 2018, 1703385.

(34) Bozyigit, D.; Yazdani, N.; Yarema, M.; Yarema, O.; Lin, W. M. M.; Volk, S.; Vuttivorakulchai, K.; Luisier, M.; Juranyi, F.; Wood, V. Soft Surfaces of Nanomaterials Enable Strong Phonon Interactions. Nature 2016, 531, 618-622.

(35) Tress, W.; Yavari, M.; Domanski, K.; Yadav, P.; Niesen, B.; Baena, J. P. C.; Hagfeldt, A.; Graetzel, M. Interpretation and Evolution of Open-Circuit Voltage, Recombination, Ideality Factor and Subgap Defect States during Reversible Light-Soaking and Irreversible Degradation of Perovskite Solar Cells. Energy Environ. Sci. 2018, 11, 151-165.

(36) Tress, W.; Leo, K.; Riede, M. Dominating Recombination Mechanisms in Organic Solar Cells Based on ZnPc and C60. Appl. Phys. Lett. 2013, 102, 163901.

(37) Giordano, F.; Abate, A.; Baena, J. P. C.; Saliba, M.; Matsui, T.; Im, S. H.; Zakeeruddin, S. M.; Nazeeruddin, M. K.; Hagfeldt, A.; Graetzel, M. Enhanced Electronic Properties in Mesoporous TiO2 via Lithium Doping for High-Efficiency Perovskite Solar Cells. Nat. Commun. 2016, 7, 10379. 